\title{
Assessing an e-Learning and b-Learning Model - A Study of Perceived Satisfaction
}

\author{
C. Quintas, I. Fernandes Silva, and A. Teixeira
}

\begin{abstract}
This study analyzes a postgraduate program, which has moved from face-to-face to b-learning and e-learning model, which has proved challenging for both students and lecturers in terms of adapting to the new environment.

Our aim is to analyze these processes, initially through a medium-term study on students' perceived satisfaction within the use of a Virtual Learning Environment and a social network.

We conducted semi-structured interviews to students to verify their perceived satisfaction on the program content and structure, as well as on its teaching methodology. We aimed to assess how useful students considered the new tools, articulating first and second stages of Kirkpatrick's Evaluation Model (Kirkpatrick, 1998).

Taking the results coming from our reading of learning processes, we have then moved on to a second stage, focusing on evaluation of learning, i.e. through analysis of the grades obtained by the students. Hands-on and practical work are determinant for the assessment of learning, in such a way that the objectives held by each subject are fulfilled. The evaluations showed positive results, showing no differences between the students on an e-learning format and those on the b-learning method.
\end{abstract}

Index Terms-Computer supported collaborative learning, blended-learning, e-learning, perceived satisfaction, learning evaluation model.

\section{INTRODUCTION}

In this paper we intend to analyze students' perceived satisfaction, together with the evaluation procedure in face of the results obtained in the context of a Post-Graduate Program in Translation Studies, offered by Universidade Autónoma de Lisboa, in a b-learning format. Our key concept - "perceived satisfaction" - is to be looked at both globally and taking into account the specificities inherent to the various electronic tools at stake.

The need to master technology today is unquestionable, as it is mirrored in the expectations of every social, academic and professional agent. It is significant to stress that, particularly in the case of translators, the need to master Information and Communication Technology (ICT) is joined by the necessity to possess other skills, such as what Miliszewska [1] has called "self-reliance". This includes an "awareness of the changing world of work, taking

Manuscript received June 12, 2015; revised January 18, 2016. This work was supported in part by the Instituto Politécnico de Setúbal.

C. Quintas is with Instituto Politécnico de Setúbal, Setúbal, Portugal (e-mail: celia.quintas@esce.ips.pt).

I. Fernandes Silva is with Universidade Autónoma de Lisboa, Lisbon, Portugal (e-mail: isilva@autonoma.pt).

A. Teixeira is with Universidade Europeia, Laureate Universities, Lisbon, Portugal (e-mail: ana.luisa.teixeira@europeia.pt). responsibility for their own career and with learning throughout all stages of life" [1]. To evaluate a learning model in such a way, one must also assess how technologically innovative are the training and the skills, given today's growing competitive and technologically sophisticated global marketplace [2]. As a consequence of that, Galloway concludes that "The value of technological innovation as a factor in a company's growth has changed the way the ownership of intellectual property is regarded, especially in the past decade" [2].

It then becomes clear that the need to master such information technologies is met with the students' necessary role of producing knowledge.

Our approach is based on Kirkpatrick's study in 1998, which sustains that it is possible to evaluate training at four different levels: the students' / trainees' satisfaction; the learning process; the changes and impact on individual behavior; and, finally, the impact on organizations [3]. Taking this author's positioning as a starting point, we will analyze the first two evaluation stages he proposes: 1). the students' perceived satisfaction in face of the training offered, which includes the tools used, as well as the pedagogical dynamics employed; 2). And secondly, we will understand a possible connection between the learning process and the final assessment results obtained. The concept of "perceived satisfaction", therefore, remains as a fundamental key factor in our proposed analysis.

We will bear in mind the variation inherent to the level of satisfaction concerning e-learning systems, as Kiam-Sam, Kwok-Wing and Derek have concluded [4]. These researchers have advocated the need to improve the online learning system, by structuring and organizing it more, so as to avoid students' demotivation and to boost the learning process instead.

Our study is based on the results of four semi-structured interviews out of the nine students we had interviewed. We have proceeded with an exploratory qualitative analysis of such contents as well as the final assessment results obtained by the students, within a f2f, e-learning and b-learning environment.

We have divided our paper into four sections: introduction, literature review, description of the study and conclusions.

\section{LITERATURE REVIEW}

\section{A. The Graduate Program in Translation Studies}

Having started in the academic year of 2003/2004, the Post-Graduate Program in Translation Studies offered by Universidade Autónoma de Lisboa has been constantly 
evolving and changing to meet the students' needs, both academically and professionally speaking.

In 2013-2014, students were introduced to a new software, WizIQ@, an online learning platform that turned out to be quite beneficial to students. Through WizIQ@ , classes can be attended on a video conference format and are then recorded, so that students can view them later on, if and when they need to. The innovative factor brought by WizIQ(C) is the combination of two distinct learning approaches/realities in one synchronous session. Lecturer and students from the classroom therefore meet the others who are online, possibly in a different city or country.

In addition to WizIQ $\odot$, students also access the university's Moodle platform, posting their work, questions, comments, and being able to communicate with each other and with the teachers.

Individual wikis have been set up as an optional possibility, as students are taught how to create and use them. They may thereby collect significant resources for their future professional lives, structuring useful repositories and possibly taking their first steps in giving form to their professional websites.

The academic year of 2013-2014 has included an additional tool in our program. It has been noticed that participants in previous editions longed for a chance to nurse a group spirit, something that, given the distance separating them and their own personal and professional lives, seemed difficult to achieve. We have then recurred to a social network, creating a Facebook page, through which some information is exchanged and social networking is more easily made viable.

What is it then that makes up for a successful teaching model? It has become clear to our understanding that, as Béres has stated, pedagogical models call for, both good quality materials and solid methodology which is adequate to students' needs [5]. The question then remains: have we indeed been able to meet the students' expectations? Are their needs being answered to through such a diversity of learning environments? Has the "team spirit" actually taken place through a successful bridging of this "virtual gap"? Can we really say that learning outcomes agree with course objectives?

We have searched for answers to these questions by the only possible and logical means: a qualitative study on students' perceived satisfaction

\section{B. Evaluation Model and Perceived Satisfaction}

When you submit your final version, after your paper has been accepted, prepare it in two-column format, including figures and tables. Evaluating training is of extreme importance so as to understand its effectiveness and to allow for the design of effective training models. One of the most used evaluation models on training programs is that developed by Donald L. Kirkpatrick in 1998, which includes four stages.

The first stage is called reaction, in which students assess their satisfaction of the training process, an immediate evaluation based on perceived satisfaction. The second stage is called Learning, which focuses on the results of classroom learning (again an immediate evaluation within the training process). The third stage is called behavior, i.e., focuses on the changes that the training has led to in terms of job behavior. The fourth stage is that on concrete results regarding the cutting of costs and enhancement of quality and quantity in training [3].

In terms of the first stage, the studies on student perceived satisfaction have increased as a result of the growing interest in this area by Education Sciences and Management. According to Souza and Reinert several elements may influence student satisfaction, both negatively and positively [6]. These authors consider the labor market, a good study plan, meeting student expectations, the lecturers and their knowledge, together with lecture planning, teaching methodology and means of interaction as positive elements, whereas poor organization and unprepared lecturers, who do not try to meet student needs, are considered as having negative effects on student perceived satisfaction. In their study, Kiam-Sam, Kwok-Wing and Derek concluded that student satisfaction towards e-learning was not homogeneous [4]. In fact, face-to-face learning was still the preferred regime and that student perceived satisfaction was linked to program organization and structuring [4].

In our study, stages 1 and 2 of Kirkpatrick's model will be analyzed in different learning contexts, namely f2f, e-learning and b-learning.

\section{Learning approaches: Face-to-Face,}

Blended-Learning and e-Learning

In our globalized society, the digital is used for personal (leisure), educational and/or professional purposes. Therefore, different learning strategies are now required to integrate it into the learning and teaching experience.

The initial attempts to deliver courses in b-learning and in e-learning, though apparently innovative, still represented static ways of learning. These first courses included repositories of resources, concepts and methodologies of the traditional classroom in a virtual environment. In fact, educational institutions, teachers and learners, all experienced difficulties in changing and adapting to the new paradigm [7].

Therefore, and as students' ways of learning altered, educational institutions felt the need to adjust and embrace today's digital literacy. As Aijan and Hartshone advocate, 2.0 web tools and the Internet provide a plethora of resources which may help in the teaching/learning process [8]. Moreover, collaboration, exchange of knowledge through interaction and dialog produce knowledge, regardless of the environment, i.e., whether f $2 \mathrm{f}$ or in a computer-mediated environment [9].

Additionally, understanding different learning styles and strategies and their effectiveness has become even more crucial, since the choice of specific strategies must take into account aspects such as: educational aims, students' prior knowledge, and learning styles [10]. As Morgan and Morgan indicate, the combination of different teaching methodologies may influence student performance and satisfaction [11].

Before we start discussing blended-learning (b-learning), we must understand its meaning and its social and cultural implications. Nowadays, face-to-face (f2f) learning is described as "traditional," whereas e-Learning is now viewed as offering new and advantageous means of communicating and exchanging knowledge. 
Pollard and Hillage describe e-learning as "the delivery and administration of learning opportunities and support via computer, networked and web-based technology to help individual performance and development." The fact that $\mathrm{f} 2 \mathrm{f}$ and e-Learning both have advantages has led to a combined learning methodology - b-learning [12].

According to the above mentioned scholars, the use of ICT allows for student-centred autonomous learning and for the lecturer becoming a facilitator. This alters completely the role of the lecturer as a leader and, keeper of knowledge and, consequently, the whole teaching and learning process. The use of ICT opens new doors to lecturers, who also benefit from a continued sense of autonomy. Students and lecturers "learn by doing" and acquire an increasing sense of autonomy.

However, e-learning has been faced with reluctance by both teachers and learners derived from individuals' concerns regarding the use of technology, the fact that they cannot connect with others for continuous backup; that they are remotely monitored and feel bored by excessive information.

The b-learning approach has been seen as an answer to some of these drawbacks, because lecturers and learners can conciliate the advantages of computer-mediated education and of face-to-face interaction. B-learning, as many studies indicate, is a more productive approach than traditional and e-learning alone [13], as it promotes effectiveness, enhances the quality of teacher-learner interaction, and allows students and teachers to provide/receive feedback in time [14], [15].

\section{THE STUDY}

\section{A. Methodology}

Ours is an ongoing qualitative study based on exploratory data analysis: we have analyzed a set of interviews conducted to students so as to assess their perceived satisfaction and the effect of ICT tools on their learning.

Analysis was made of four semi-structured interviews as well as of the grades obtained by students attending the program.

In terms of the interviews and the script, we adapted model by Kiam-Sam, Kwok-Wing and Derek [4], which focused on perceived satisfaction regarding Tools; Prior experience; Effect on learning of ICT tools. Analysis of the interviews was carried out using content analysis software: ALCESTE (Analyse Lexicale par Context d'un Ensemble de Segments de Texte).

This software carries out its analysis based on calculations of word co-occurrence in text segments, and distinguishes word classes that identify discourse specificities [16].

In terms of the grades, as per Kirkpatrick's second stage, we analyzed the final grades obtained by students in the first and second semester course units, divided by the regime they attended the program.

\section{B. Findings and Discussion}

The analysis carried out in ALCESTE allowed us to divide the corpus into three rather classes:

Class 1 - which we designated e-Learning and Communication - focuses on the dynamics of learning using the e-learning platform and students' interaction with the lecturers;

Class 2 - which we designated Face-to-face sessions and Communication - focuses on face-to-face teaching and learning and on communication;

Class 3 - which we designated Learning Rhythms and Tools and whose categories are more diffuse - focuses on the e-learning tools and on learning rhythms.

As mentioned earlier, ALCESTE calculates co-occurrence of segments and shows which have more statistical significance.

As such, in Class 1, there are eight units with significance: Moodle with an explaining ability of 0.51 of the corpus, dúvida (doubt) (0.49), lecturer (professor) (0.41). WizIQ@ (0.24), exemplo (example) $(0,24)$ e-learning $(0.26)$, faculdade (faculty) (0.24); in Class 2, there are three units with significance: momento (moment) (0.43), comunicação (communication) (0.41) and presencial (face-to-face) (0.34); and in Class 3, five units have significance: semana (week) (0.45), importante (important) (0.41), curso (program) (0.36), contacto (contact) (0.23), informação (information) (0.22).

Communication is, therefore, present in all three classes, though the data in Class 3 is more diffuse. In Class 1, communication using Moodle is referred to, together with answers (responder) by the lecturer (professor); in Class 2 , $\mathrm{f} 2 \mathrm{f}$ communication (presencial) is mentioned in relation to time (momento); in Class 3, time is also present (semana) though associated with learning rhythm and tools and their importance for "personal" interaction.

In conclusion, different tools are used for different objectives: Moodle is linked to learning materials and to learning; for personal and professional interaction, Facebook is the preferred tool; and WizIQ represents the possibility to replace or complement $\mathrm{f} 2 \mathrm{f}$ sessions, regarded as the most important.

In regards to the analysis of student grades, our conclusion is that there is no significant difference in terms of the range of grades (14-18 out of 20) awarded to students who attended the Post-Graduate Program in Translation either f2f, in b-learning or e-learning regimes

\section{CONCLUSION}

Results show that there is no consensus in regards to that perceived satisfaction on b-learning and e-learning systems. Nevertheless, the general conclusions regarding the first stage of evaluation, according to Kirkpatrick [3], are that:

1) Students prefer face-to-face learning, as it allows for immediate interaction with lecturers and classmates;

2) Technical problems may hinder communication and online interaction.

3) E-Learning is considered a valid alternative;

4) Students consider that e-learning poses some advantages, that the process is well organized and that it meets their expectations.

As far as Kirkpartick's second stage of evaluation is concerned (evaluating learning outcomes and students' grades) [3], we realize that the grades obtained in the different course units are rather high (between 14 and 18 out of 20), 
there being no significant difference depending on the regime they attended the program (f2 $\mathrm{f}$, b-learning or e-learning). Finally, students considered relevant that classes were recorded and available for viewing at their convenience.

We agree with Kiam-Sam, Kwok-Wing and Derek [4], whose study, like ours, evidenced that student satisfaction towards e-learning was not homogeneous, that face-to-face learning is still the preferred regime and that perceived satisfaction is highly dependent on students' opinion regarding program organization and structuring. Moreover, we support Souza and Reinert's position in regards to some elements having a positive or a negative effect on student satisfaction [6]. Among those positive elements referred to by the above mentioned scholars are the lecturers, their knowledge, lecture planning, teaching methodology and means of interaction, as well as teaching perception

\section{REFERENCES}

[1] I. Miliszewska, "ICT skills: An essential graduate skill in today's global economy?" in Proc. the Informing Science \& IT Education Conference (InSITE), 2008, pp. 101-109.

[2] D. Galloway, "Evaluation distance delivery and e-learning: Is kirkpatrick's model relevant?" Performance Improvement, vol. 44, no. 4, ABI/INFORM, April 2005.

[3] D. Kirkpatrick, "Evaluating training programs: The four levels," San Francisco: Berret-Koehler, 1998.

[4] H. Kiam-Sam, L. Kwok-Wing, and H. Derek, "Students' satisfaction and perceived learning with a web-based course," Educational Technology \& Society, vol. 6, no. 1, pp. 116-124, 2003.

[5] I. Béres, "Learning styles in e-learning," OIK, vol. I, pp. 71-78, 2009.

[6] S. A. Souza and J. N. Reinert, "Avaliação de um curso de ensino superior através da satisfação/insatisfação discente," Avaliação, Campinas, vol. 15, no. 1, pp. 159-176, 2010.

[7] J. R. Duarte and A. F. Beaufils, "Flip or toss: The importance of assessment in b-learning courses," in Proc. 5th International Conference of Education, Research and Innovation, 2012, pp. 4509-4514.

[8] H. Aijan and R. Hartshorne, "Investigating faculty decision to adapt web 2.0 technologies: Theory and empirical tests," Internet and Higher Education Journal, Elsevier, vol. 11, pp. 71-80, 2008.

[9] M. Stevenson and J. Hedberg, "Learning and design with online real-time collaboration," Educational Media International, vol. 50, no. 2, pp. 120-134, 2013.

[10] C. Lowerison, R. Cote, and A. Lavoie, "Revisiting theory for e-learning," The e-Learning Handbook, Pfeiffer, 2008, pp. 425-447.

[11] K. Morgan and M. Morgan, "The challenges of gender, age and personality in e-learning," The Sage Handbook of e-learning Research, London, 2007, pp. 132-136.

[12] E. Pollard and J. Hillage, Exploring e-Learning, Brighton: Institute for Employment Studies, 2001

[13] M. Balci and H. Soran, "Students'opinions on blended learning," Turkish Online Journal of Distance Education, vol. 10, no. 1, pp. 21-35, 2009.

[14] J. Gómez and M. Igado, "Blended learning: The key to success in a training company," International Journal of Instructional Technology and Distance Learning, vol. 5, no. 8, 2008.
[15] I. F. Silva, C. Quintas, A. Teixeira, and J. R. Duarte, "Meeting students' expectations in a changing teaching and learning environment - A study on student perceived satisfaction," in Proc. 8th International Conference on Technology, Education and Development, 2014, pp. 6342-6350.

[16] A. Nascimento and P. Menandro, "Lexical analysis and content analysis: a proposal for conjugate," Estudos e Pesquisas em Psicologia, UERJ.RJ, Ano 6, 2006.

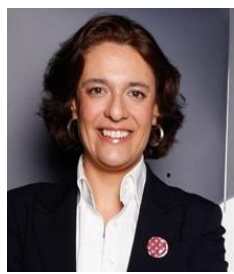

Célia Quintas was born in Lisbon in 1967. After graduating in sociology by Universidade Autónoma de Lisboa (UAL), she completed her masters in human resources management at ISCTE, Instituto Universitário de Lisboa in 1996 and her $\mathrm{PhD}$ in economics at UAL in 2012.

She is adjunct professor at Instituto Politécnico de Setúbal. She works at the Institution's Business School and she has lecturing human resources management in the bachelor in human resources management and knowledge management in the master's degree since 2012. She is auxiliary professor at UAL, where she has lectured since 1992. She has published several papers.

Prof. Quintas is a member of APSIOT - Associação Portuguesa de Profissionais em Sociologia Industrial, das Organizações e do Trabalho (a Portuguese Sociological Association).

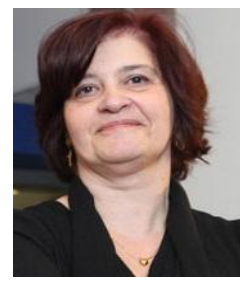

Isabel Fernandes Silva was born in Lisbon in 1963 Having graduated in foreign languages and literatures, major in English and German, from the Faculty of Arts, University of Lisbon, in 1986, she completed her $\mathrm{PhD}$ in the University of Salamanca, Spain, in 1998 with a thesis entitled "The British Abroad in E. M. Forster's Fiction".

She is associate professor at Universida de Autónoma de Lisboa, Portugal, since 1986, where she has taught general English and English for specific purposes for over 20 years. She is also the coordinator of the English and Portuguese language courses and of the post-graduation in translation at the referred university. She has published several papers on ESL, on linguistics and on ICT and language learning. Her research interests include technology-enhanced learning, e-learning, language acquisition and translation.

Prof. Fernandes Silva is a member of EST - European Translation Society and of the International Council for Educational Media

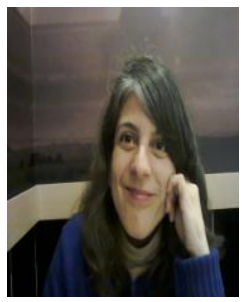

Ana Teixeira was born in Maputo, Mozambique, in 1972. She graduated in foreign languages and literatures - English and German, from the Faculty of Letters, University of Lisbon, in 1994, having completed a master's program in American studies, in 1996. She then earned a fulbright scholarship and completed a $\mathrm{PhD}$ program in African studies, at Temple University, Philadelphia (2001). Dr Teixeira is an assistant professor at Universidade Europeia, Laureate International Universities, where she mainly teaches ESL to Portuguese students (elementary to advanced). Her main research interests are gender and African studies - to which she has fully dedicated herself within a two-year post-doctoral reasearch project - language acquisition and translation. She has some publications. 